\title{
The Role of the Ankyrin-Binding Protein NrCAM in Node of Ranvier Formation
}

\author{
Andrew W. Custer, ${ }^{1}$ Katia Kazarinova-Noyes, ${ }^{2}$ Takeshi Sakurai, ${ }^{3}$ Xiaorong Xu, ${ }^{1}$ William Simon, ${ }^{2}$ Martin Grumet, ${ }^{4}$ and \\ Peter Shrager ${ }^{1}$ \\ Departments of ${ }^{1}$ Neurobiology and Anatomy and ${ }^{2}$ Biochemistry and Biophysics, University of Rochester Medical Center, Rochester, New York 14642 , \\ ${ }^{3}$ Department of Neurobiology, Mount Sinai School of Medicine, New York, New York 10029, and ${ }^{4}$ W. M. Keck Center for Collaborative Neuroscience, \\ Rutgers University, Piscataway, New Jersey 08854
}

\begin{abstract}
Molecular events involved in $\mathrm{Na}^{+}$channel clustering at the node of Ranvier have been investigated during early development. NrCAM, an ankyrin $_{\mathrm{G}^{-}}$-binding protein, precedes $\mathrm{Na}^{+}$channels at cluster sites adjacent to the tips of Schwann cell processes. Both $\mathrm{Na}^{+}$channel and

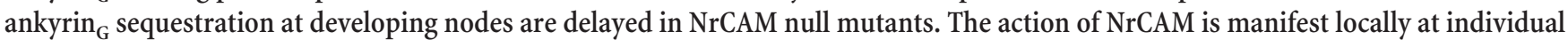
nodes, rather than affecting overall neuronal expression, and is linked to glial interactions. During remyelination, $\mathrm{Na}^{+}$channel clusters at new nodes are initially labile, and anchoring to the cytoskeleton appears to grow progressively with time. The distance between $\mathrm{Na}^{+}$ channel clusters across remyelinating Schwann cells (nascent internodes) increases markedly from 83 to $274 \mu \mathrm{m}$ during node formation, arguing against schemes in which the loci of nodes are fixed in advance by the axon. A hypothesis for node formation in which axonal $\mathrm{Na}^{+}$ channels move by lateral diffusion from regions of Schwann cell contact, with clustering dependent on linkage to the cytoskeleton by ankyrin $_{\mathrm{G}}$, is proposed and tested in a computational model. To match experimental measurements, this latter reaction needs fast kinetics, and the early arrival of $\mathrm{NrCAM}$ is postulated to contribute to this requirement.
\end{abstract}

Key words: NrCAM; node; Na channel; ankyrin; cluster; glia

\section{Introduction}

The node of Ranvier is characterized by the compartmentalization of different proteins into sharply defined subcellular regions. Included among these components are the voltage-dependent ion channels that underlie excitability. It has become increasingly clear that these channels are part of large heteromultimeric complexes that contain intracellular scaffolding, adapter, and cytoskeletal proteins and extracellular matrix elements, as well as several transmembrane proteins. There is also growing evidence that glial interactions are essential for the localization of these channels, but the cellular and molecular mechanisms remain debated and numerous details are unknown. Recently, new ideas for the molecular events that play important roles in node formation have been proposed. $\mathrm{Na}^{+}$channels are bound to the spectrinactin cytoskeleton via ankyrin ${ }_{\mathrm{G}}$, a multidomain adapter protein (Bennett and Lambert, 1999; Malhotra et al., 2000). Additionally, several Ig superfamily membrane proteins, including NrCAM and neurofascin (Rathjen et al., 1987; Grumet et al., 1991; Sakurai et al., 2001), are found at nodes and bind ankyrin ${ }_{\mathrm{G}}$ within their intracellular domains (Davis and Bennett, 1994). NrCAM and

Received June 19, 2003; revised Sept. 9, 2003; accepted Sept. 11, 2003

This work was supported by National Institutes of Health Grants NS17965 (P.S.) and NS38949 (M.G.). We thank Deana Amico, Joanne Babiarz, and Andrea Venosa for excellent technical assistance. Drs. S. Rock Levinson, Samuel E. Lux, Elior Peles, Melitta Schachner, and James S. Trimmer provided generous gifts of antibodies.

Correspondence should be addressed to Dr. Peter Shrager, Department of Neurobiology and Anatomy, P.0. Box 603, Room 4-5428, University of Rochester Medical Center, 575 Elmwood Avenue, Rochester, NY 14642. E-mail: pshr@mail.rochester.edu.

Copyright $\odot 2003$ Society for Neuroscience $\quad$ 0270-6474/03/2310032-08\$15.00/0 neurofascin have been proposed to act as pioneer molecules in node formation because, at postnatal day 2 (P2) in sciatic axons, they were found to cluster at some sites before $\mathrm{Na}^{+}$channels and ankyrin $_{\mathrm{G}}$ (Lambert et al., 1997). Furthermore, NrCAM-Fc fusion proteins block $\mathrm{Na}^{+}$channel clustering in a sensory neuronSchwann cell coculture system (Lustig et al., 2001b). Bennett and coworkers have provided a possible molecular mechanism for these interactions by identifying a crucial tyrosine residue in both NrCAM and neurofascin, and a similar site has been identified in the $\mathrm{Na}^{+}$channel $\beta 1$-subunit (Garver et al., 1997; Bennett and Lambert, 1999; Jenkins et al., 2001; Malhotra et al., 2002). Phosphorylation of this residue inhibits ankyrin binding, and thus spatially distinct activation of specific tyrosine kinases and phosphatases could control mobility and anchoring of $\mathrm{Na}^{+}$channels and associated cell adhesion molecules (Jenkins et al., 2001).

In this paper, we explore several of these ideas. The functions of ankyrin ${ }_{\mathrm{G}}$ and NrCAM during development of nodes of Ranvier are examined. The timing of NrCAM localization relative to that of other nodal proteins is measured quantitatively throughout the early developmental period of the PNS, and its function is then tested in a null mutant mouse. Other experiments are designed to distinguish between roles of ankyrin $_{\mathrm{G}}$ in clustering versus stability of $\mathrm{Na}^{+}$channels at nodes. Finally, the rate of Schwann cell growth is measured during remyelination, and this experiment provides a means of distinguishing between two fundamentally different mechanisms of nodal development. These results, and a new computational model, support the idea that clusters form as axonal $\mathrm{Na}^{+}$channels move laterally by diffusion 
in the plasma membrane from regions of contact with myelinating glia and are then immobilized very rapidly adjacent to the tips of glial processes. This latter step may be promoted by the early appearance of NrCAM.

\section{Materials and Methods}

Immunocytochemistry. Animals were killed by $\mathrm{CO}_{2}$ inhalation, and sciatic nerves were dissected, desheathed, and dissociated into single fibers with collagenase-dispase [3 $\mathrm{mg} / \mathrm{ml}, 15-30 \mathrm{~min}$, room temperature (RT)]. Axons were teased over spots of Cell-Tak (Collaborative Research, Bedford, MA) and fixed in 4\% paraformaldehyde (30 min, RT). After washing in phosphate buffer $(\mathrm{PB})(0.1$ and $0.05 \mathrm{M})$, the tissue was dried. To improve labeling of ankyrin $_{\mathrm{G}}$, some samples were soaked in $20 \%$ sucrose (in $0.1 \mathrm{M} \mathrm{PB}$ ), frozen, thawed, and washed as above before drying. Optic nerves, and some sciatic nerves, were prepared for cryosectioning by fixing after dissection in $4 \%$ paraformaldehyde for $30 \mathrm{~min}$ at RT or, alternatively, $15 \mathrm{~min}$ at RT followed by methanol $\left(5 \mathrm{~min},-20^{\circ} \mathrm{C}\right)$. Nerves were sunk successively in 20 and $30 \%$ sucrose, frozen in O.C.T., sectioned at $10 \mu \mathrm{m}$, mounted on gelatin-coated coverslips, and dried. All preparations were permeabilized in $0.1 \mathrm{M} \mathrm{PB}, 0.3 \%$ Triton X-100, and $10 \%$ goat serum (PBTGS). All antibodies were diluted in PBTGS, and washes between applications were also with PBTGS. In most experiments, axons were labeled with two primary antibodies, one rabbit polyclonal and one mouse monoclonal, and appropriate anti-rabbit or antimouse IgG secondary antibodies conjugated to fluorophores were applied after washing. In cryosections of mouse sciatic nerve, the background was very high when anti-mouse secondary antibodies were used, presumably attributable to the presence of high levels of mouse nonimmune IgG. To label the latter preparations, we used a technique similar to that used previously in this laboratory, using two rabbit polyclonal primary antibodies (Poliak et al., 1999; Rasband et al., 1999). After incubation with the first primary antibody and three washes for $3 \mathrm{~min}$ each, an Fab-FITC secondary antibody (Accurate Chemicals, Westbury, NY) is applied at high concentration (1:25) for $2 \mathrm{hr}$. After six washes for $3 \mathrm{~min}$ each, the second primary antibody is applied and washed, and then an Fab-Cy3 secondary antibody (Accurate Chemicals) is used at 1:4000 for $30 \mathrm{~min}$. All slides were examined with a Nikon (Tokyo, Japan) Microphot fluorescence microscope fitted with a Hamamatsu (Bridgewater, NJ) C4742-95 cooled CCD camera controlled by Image-Pro (Media Cybernetics, Silver Spring, MD). Whenever images were compared for the relative expression of a particular protein, they were combined and thereby processed identically in Image-Pro or Photoshop (Adobe Systems, San Jose, CA).

Antibodies. Primary antibodies have all been described previously and included the following: polyclonal anti-pan $\mathrm{Na}^{+}$channels (gift from Dr. S. Rock Levinson, University of Colorado, Denver, CO) (DugandzijaNovakovic et al., 1995); monoclonal anti-pan $\mathrm{Na}^{+}$channels (gift from Dr. James S. Trimmer, University of California, Davis, CA) (Rasband et al., 1999); polyclonal anti-contactin-associated protein 1 (caspr1) (gift from Dr. Elior Peles, Weizmann Institute of Science, Rehovot, Israel) (Einheber et al., 1997; Peles et al., 1997); polyclonal anti-NrCAM (Lustig

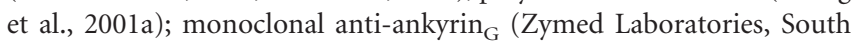

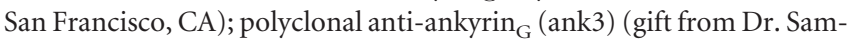
uel E. Lux, Children's Hospital, Boston, MA) (Peters et al., 1995); and monoclonal anti-myelin associated glycoprotein (MAG) (gift from Dr. Melitta Schachner, Universtat Hamburg, Hamburg, Germany) (Poltorak et al., 1987).

Electrophysiology. Compound action potentials were measured by drawing each end of a nerve into a suction electrode, using one side for stimulation and the other for recording. Nerves were bathed in oxygenated Locke's solution, containing the following (mM): $154 \mathrm{NaCl}, 5.6 \mathrm{KCl}$, $2 \mathrm{CaCl}_{2}, 5$ D-glucose, and 10 HEPES, $\mathrm{pH}$ 7.4. Bath temperature was controlled with a proportional heater. Sweeps were collected and analyzed in a laboratory computer. Additional details have been published previously (Rasband et al., 1999; Vabnick et al., 1999).
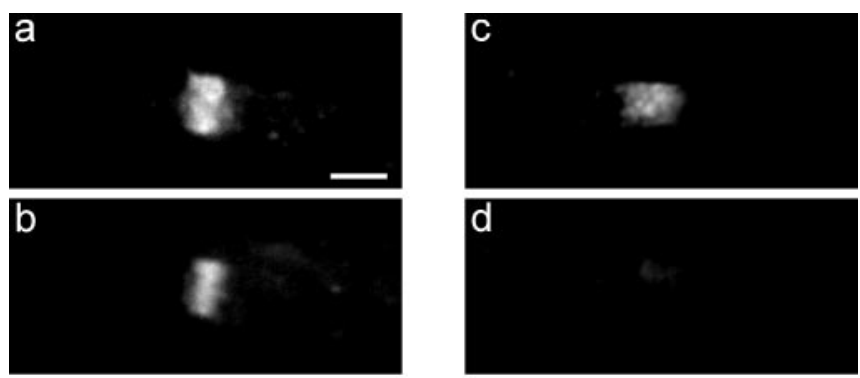

d
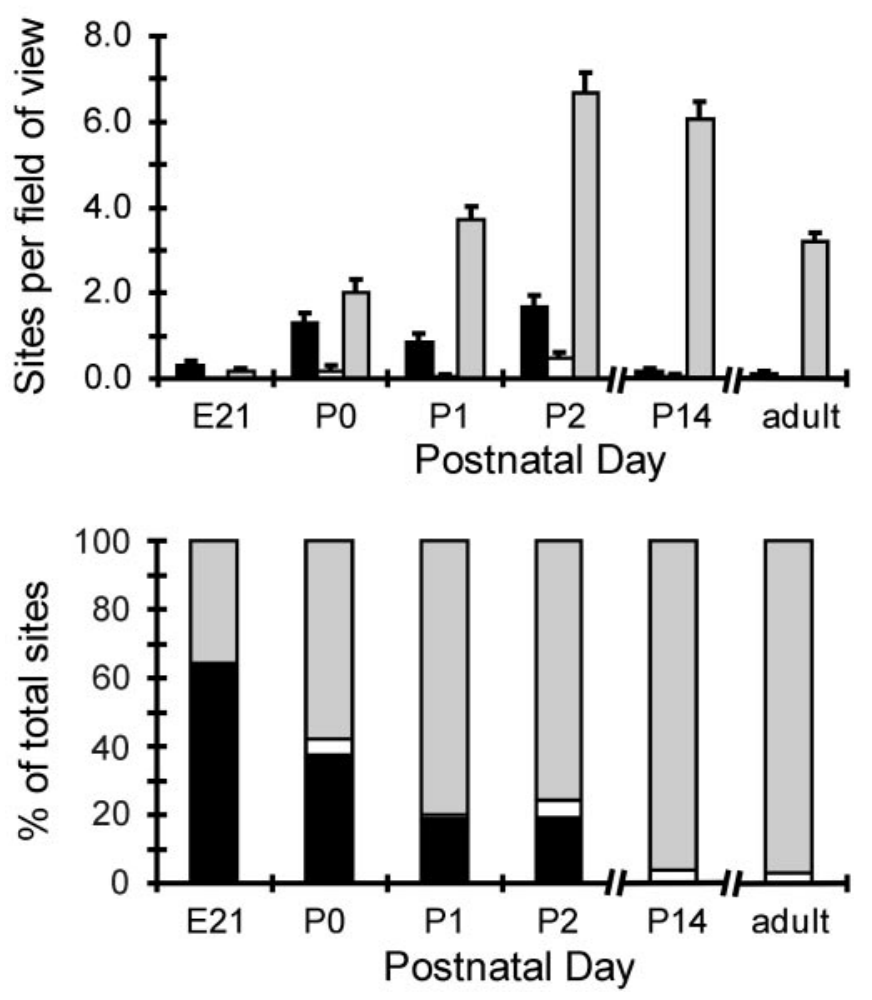

Figure 1. Early localization of NrCAM at nodes of Ranvier. $a-d$, Immunofluorescence localization of $\operatorname{NrCAM}(a, c)$ and pan $\mathrm{Na}^{+}$channels $(b, d)$ at two nodal sites at P0. At sites $a$ and $b$, both $\mathrm{NrCAM}$ and $\mathrm{Na}^{+}$channels are clustered. At sites $c$ and $d$, only NrCAM is detected. The graphs summarize data from E21 to the adult. The top graph plots the number of sites in each category per field of view, and the bottom graph gives the data as a percentage of total sites for each day. Black bars, NrCAM alone; gray bars, both NrCAM and $\mathrm{Na}^{+}$channels; white bars, $\mathrm{Na}^{+}$channels alone, NrCAM not detected. Thirty fields of view were analyzed at each age. Total number of nodes analyzed are as follows: E21, 14; P0, 104; P1, 139; P2, 300; P14, 189; and adult, 99.

\section{Results}

The role of NrCAM at developing nodes of Ranvier

NrCAM localization at nodes of Ranvier was examined during early development of the PNS. Figure 1 shows immunofluorescence labeling of axons with antibodies to $\operatorname{NrCAM}(a, c)$ and pan $\mathrm{Na}^{+}$channels $(b, d)$. Nodes had both proteins colocalized $(a, b)$, only $\operatorname{NrCAM}(c, d)$, or only $\mathrm{Na}^{+}$channels (very rare and not shown). Nodes were placed in categories and counted within each field of view, and the results are plotted in the top graph of Figure 1. The data are replotted as percentages of the total number of nodes for each age in the bottom graph. At embryonic day 21 (E21), there are very few sites, but, at over $60 \%$ of these, only NrCAM is detected (black bars). The number of nodes increases sharply over the next few days, but the fraction with no detected $\mathrm{Na}^{+}$channels falls rapidly during this period. By P14, almost all sites have $\mathrm{NrCAM}$ and $\mathrm{Na}^{+}$channels colocalized (gray bars). The 

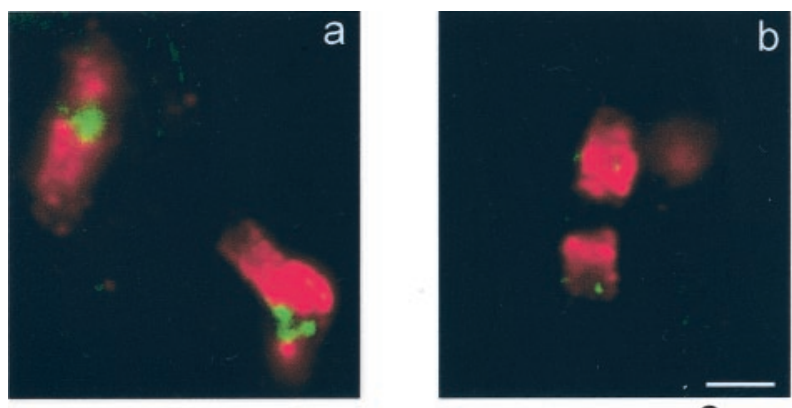

$2 \mu \mathrm{m}$

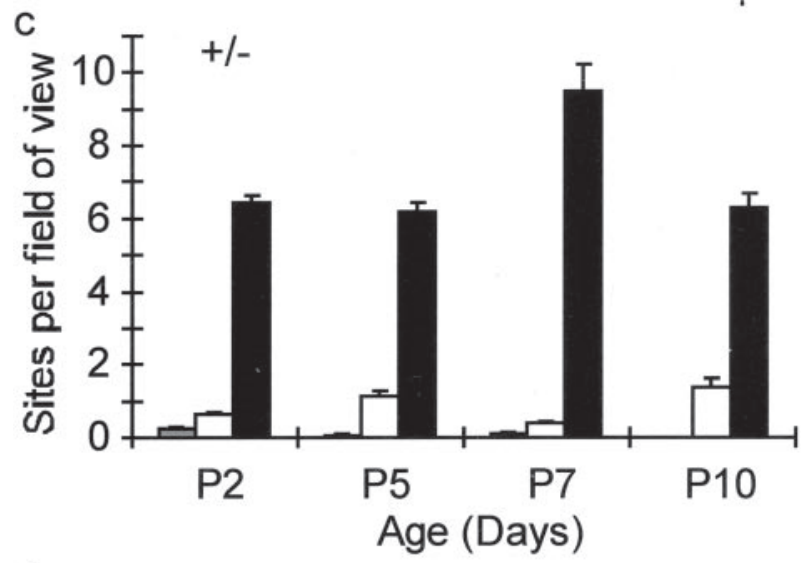

d
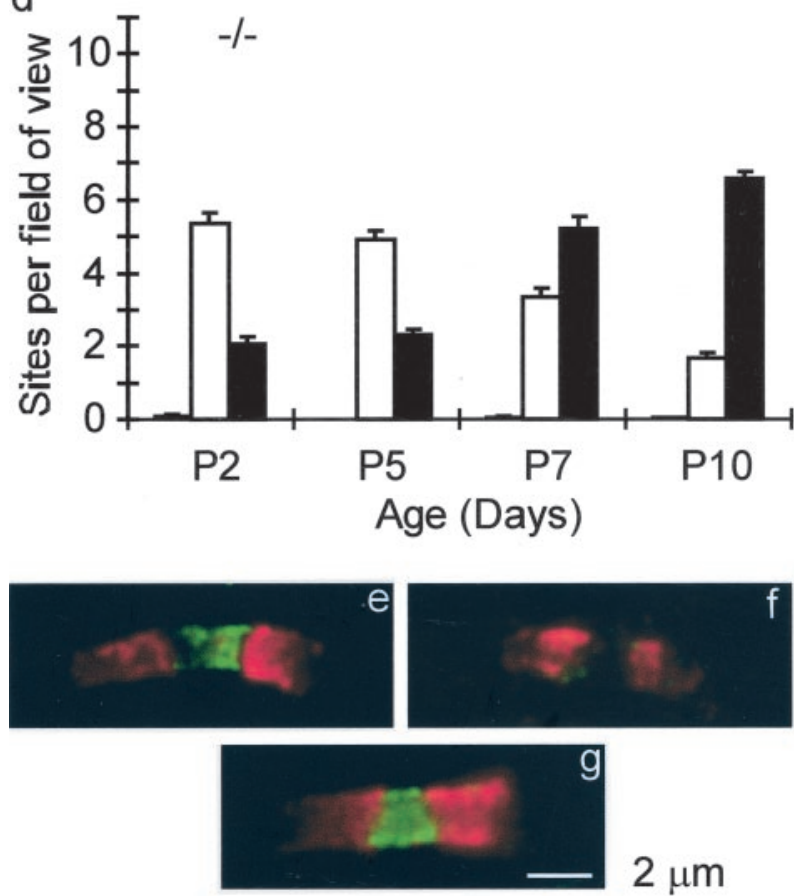

$2 \mu \mathrm{m}$

Figure 2. Delay in $\mathrm{Na}^{+}$channel and ankyrin ${ }_{\mathrm{G}}$ clustering in NrCAM null mutant mice. $a, b$, Cryosectioned sciatic nerve from a $\mathrm{P5} \mathrm{NrCAM}(-/-)$ animal, labeled for caspr1 (red) and $\mathrm{Na}^{+}$ channels (green). $a$ and $b$ images were treated identically (see Materials and Methods). $c$, $\operatorname{NrCAM}(+/-)$ animals. Number of sites per field of view were plotted versus age. Black bars, Sites with both caspr1-positive paranodes and $\mathrm{Na}^{+}$channels clustered in the nodal gap; white bars, sites with caspr-positive paranodes but no detectable $\mathrm{Na}^{+}$channel nodal cluster; gray bars, sites with $\mathrm{Na}^{+}$channels but no adjacent caspr 1 detected. $d$, Similar to c but with $\mathrm{NrCAM}$ $(-/-)$ mice. Total fields of view analyzed are as follows: $\operatorname{NrCAM}(-1-), 330$; and $\operatorname{NrCAM}$ $(+/-)$, 330. Total nodes analyzed were as follows: $\operatorname{NrCAM}(-/-), \mathrm{P2}, 451 ; \mathrm{P5}, 650 ; \mathrm{P7}, 517$; P10, 994; and $\operatorname{NrCAM}(+/-), P 2,878 ;$ P5, 440; P7, 1201; P10, 229. e, $f$, Ankyrin $_{G}$-positive and -negative nodes in developing NrCAM null mutants. caspr1 (red) and ankyrin ${ }_{G}$ (green) labeled cryosections from a P2 $\operatorname{NrCAM}(-/-)$ sciatic nerve. $g$, A node from an adult $\operatorname{NrCAM}(-/-)$ sciatic nerve stained as in $e$ and $f$. number of nodes per field of view declines after P14 because the internodal distance increases as the animal grows. The data presented here, spanning the days of earliest node formation, support the view that NrCAM acts as a pioneer molecule (Lambert et al., 1997) and show a continuous transition from sites with $\mathrm{Nr}$ CAM alone to regions of colocalization with $\mathrm{Na}^{+}$channels.

The role of NrCAM in node formation was tested further in null mutant mice (Sakurai et al., 2001). Sciatic axons were analyzed during the first postnatal week, a time of rapid development and myelination. caspr 1 immunofluorescence was used to localize early paranodes, and $\mathrm{Na}^{+}$channel immunostaining was examined in the nodal gap. Figure 2, $a$ and $b$, shows two regions from the same image of a cryosection of the sciatic nerve of a P5 $\operatorname{NrCAM}(-/-)$ animal. The caspr1-defined sites in $a$ are each associated with an $\mathrm{Na}^{+}$channel cluster, but, at the site in $b$, this accumulation is not detected. The bar graphs provide quantitative analysis. In (+/-) axons, almost all sites that have caspr1positive paranodes also have nodal $\mathrm{Na}^{+}$channel clusters at all times examined (Fig. 2c). However, in null mutants, $\mathrm{Na}^{+}$channels could not be detected at over $70 \%$ of newly forming nodes at P2 and P5 (Fig. 2d). This number dropped until, by P10, results were similar to those in $(+/-)$ mice. Genetic elimination of $\mathrm{Nr}$ CAM thus results in a significant developmental delay in $\mathrm{Na}^{+}$ channel clustering at PNS nodes of Ranvier. Ultimately, nodal expression patterns are normal in these animals, and there are no apparent abnormalities in the adult. In all cases, sites with $\mathrm{Na}^{+}$ channel clusters in the absence of corresponding caspr 1 are very rare. Tallying all caspr1-defined regions shows that deletion of NrCAM does not affect paranode formation. Thus, the total number of such zones per field of view at P5 was $7.3 \pm 0.3$ in $(+/-)$ and $7.2 \pm 0.2$ in $(-/-)$ mice.

We next asked whether ankyrin $_{\mathrm{G}}$ clustering is also delayed in the absence of $\mathrm{NrCAM}$. Figure $2, e$ and $f$, show two nodes from an $\operatorname{NrCAM}(-/-)$ sciatic nerve cryosection at P2. Ankyrin ${ }_{\mathrm{G}}$ is detectable only in $e$. Overall, ankyrin ${ }_{\mathrm{G}}$ was found in $88 \%$ (72 of 82) of nodes in (+/-) nerves at P2 but in only 26\% (23 of 88 ) of nodes in $(-/-)$ littermates. This compares well with the corresponding numbers for $\mathrm{Na}^{+}$channels from Figure 2, $c$ and $d[91 \%$ in $(+/-)$ and $28 \%$ in $(-/-)$ ]. As in the case of $\mathrm{Na}^{+}$channels, this loss of ankyrin ${ }_{\mathrm{G}}$ was only a delay, and, in adult nerves, anky$\operatorname{rin}_{\mathrm{G}}$ was detected in $92 \%$ ( 82 of 89 ) of nodes in $(+/-)$ mice and $90 \%$ (94 of 104) in (-/-) animals (Fig. $2 g$ ). We investigated whether the "missing" $\mathrm{Na}^{+}$channel clusters are axon specific (i.e., all sites within a given axon the same) or whether they vary within a given fiber. Figure 3 illustrates two developing nodes in a single fiber in a P2 NrCAM (-/-) mouse sciatic nerve. $\mathrm{Na}^{+}$ channels are detected only in the left site, in which the caspr 1 immunofluorescence is highest, suggesting that clustering is controlled independently at each nodal region and need not be uniform in a given axon.

Figure 4 shows compound action potentials recorded from sciatic nerves of $(+/-)$ and $(-/-)$ NrCAM mice at P2. These records have multiple peaks at this developmental stage, the first presumably reflecting larger axons undergoing early myelination, and the others, smaller premyelinated or unmyelinated fibers. Conduction velocity of the faster component is plotted in the bar graph. There is no significant difference between $(+/-)$ and $(-/-)$ nerves at 25 or $37^{\circ} \mathrm{C}$, despite the missing $\mathrm{Na}^{+}$channel clusters in the null mutant. There is also no significant difference in amplitude. Areas under the fast peaks were calculated and found to be the same in $(+/-)$ and $(-/-)$ nerves (data not shown). These results are consistent with the fact that NrCAM $(-/-)$ pups have no obvious behavioral phenotype, thrive, and 


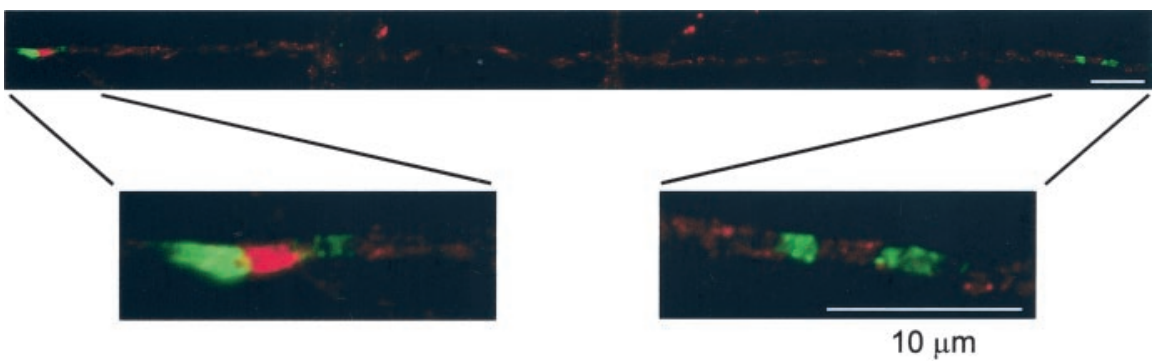

Figure 3. Local control of $\mathrm{Na}^{+}$channel clustering in the NrCAM null mutant. Top, A composite image of two consecutive nodes within a single teased sciatic axon of a P2 $\mathrm{NrCAM}(-/-)$ mouse. Green, caspr1; red, pan $\mathrm{Na}^{+}$channels. Bottom, Enlarged views of the nodes in this axon.

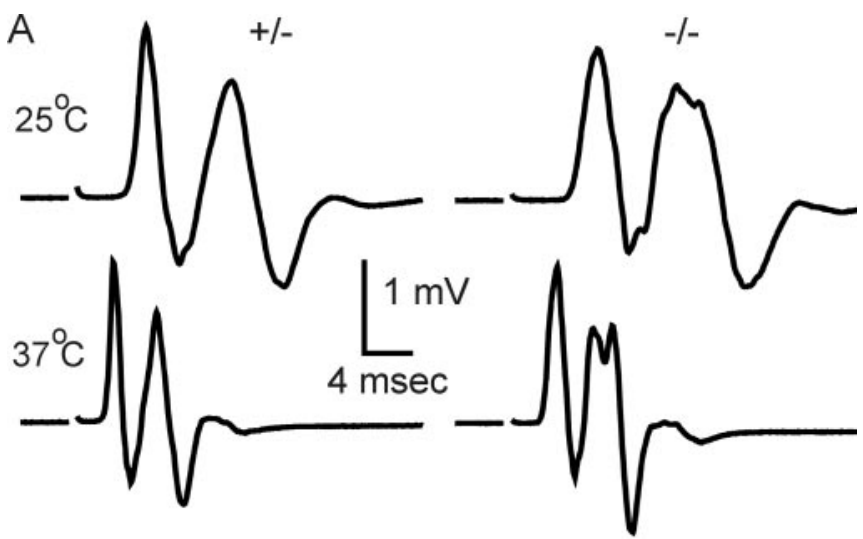

B

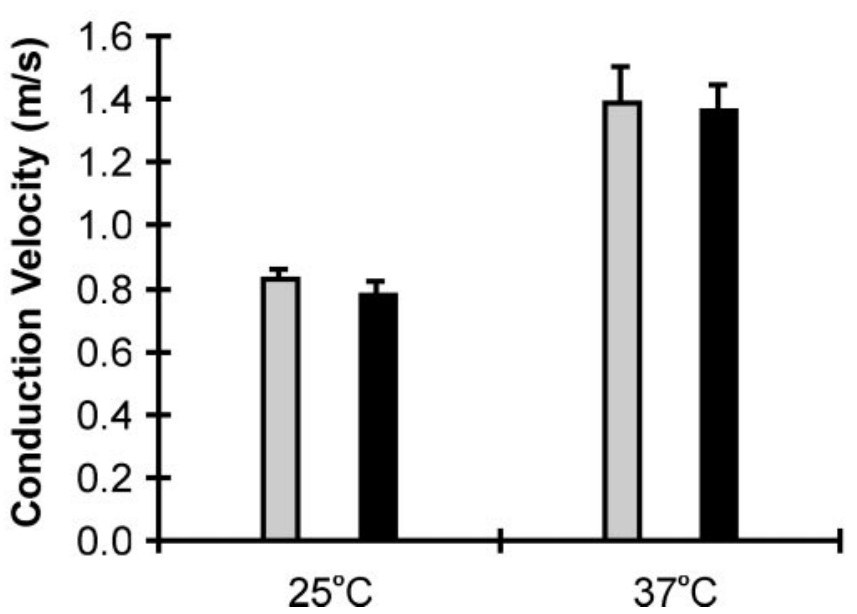

Figure 4. Conduction in developing NrCAM null mutant mice. $A$, Compound action potentials from $\mathrm{P} 2$ sciatic nerves of $\mathrm{NrCAM}(+/-)$ (left) and $(-/-)$ (right) animals at 25 and $37^{\circ} \mathrm{C}$. $B$, Conduction velocity of the faster component at 25 and $37^{\circ} \mathrm{C}$. Gray bars, $(+/-), n=12$; black bars, $(-/-), n=4$.

reach adulthood. It seems, however, unexpected in the light of the delayed clustering at nodes. The rationale for this apparent inconsistency is likely to reside in the necessity for vertebrates to maintain axonal function during the reorganization that takes place during myelination. This is treated in some detail in Discussion. In both electrophysiology and in the preceding localization experiments, we looked primarily at null versus heterozygote. Because we worked on very young pups, they could not be genotyped until the experiments were completed. Thus, in most experiments, we mated $(+/-)$ and $(-/-)$ animals to ensure ap- proximately equal numbers, and the experiments were blinded until genotyping. To test for differences between $(+/-)$ and $(+/+)$, we mated two $(+/-)$ mice and examined littermates at P2. Both immunolabeling (caspr1 and pan $\mathrm{Na}^{+}$channel) and action potentials were identical in $(+/-)$ and $(+/+)$ nerves (data not shown).

\section{Anchoring of $\mathrm{Na}^{+}$channels}

We next investigated the role of ankyrin $_{\mathrm{G}}$ in the initiation of $\mathrm{Na}^{+}$channel clustering versus its participation in stabilizing existing clusters through links to the cytoskeleton. We attempted to judge the relative arrival times of these proteins at the earliest sites of clustering in the rat sciatic nerve at $\mathrm{P} 0$. There were almost no regions in which ankyrin $_{\mathrm{G}}$ was seen in the absence of $\mathrm{Na}^{+}$channels. In some clus-

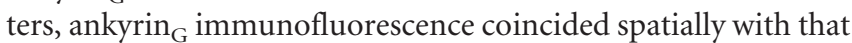
of $\mathrm{Na}^{+}$channels by over $50 \%$ (Fig. $5 a-c$ ). In others, ankyrin ${ }_{\mathrm{G}}$ labeling was barely above background in intensity and seemed more limited in overlap (Fig. $5 d-f$ ). It was not possible to quantitate this reliably, but we were able to conclude that, with the exception of a few rare sites, all $\mathrm{Na}^{+}$channel clusters at $\mathrm{P} 0$ were characterized by some degree of colocalization with ankyrin G $_{\text {. }}$ Thus, within the limitations of immunofluorescence detection, these proteins appeared to arrive virtually simultaneously.

This issue was also examined in demyelinated rat axons. In this preparation, the outer layers of myelin are damaged by exposure to lysolecithin, and macrophages then fully demyelinate affected internodes by phagocytosis (Hall and Gregson, 1971). After $\sim 8 \mathrm{~d}$, Schwann cells proliferate and begin the process of remyelination. We showed previously that, if Schwann cell division is blocked by a mitotic inhibitor, $\mathrm{Na}^{+}$channels remained clustered for at least 1 week after myelin removal from both heminodes but were dispersed by 2 weeks (DugandzijaNovakovic et al., 1995). Figure 5, $i$ and $j$, extends the survival

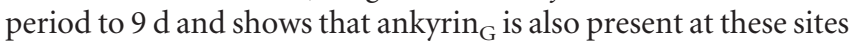
(Fig. $5 g, h$ illustrates a normal adult node for comparison). Thus, $\mathrm{Na}^{+}$channel clusters at nodes of Ranvier require myelinating glial cells for their initiation, but, in the adult, they are then very stable even after myelin removal, and the link to ankyrin ${ }_{\mathrm{G}}$ is likely to play a major role. Ankyrin ${ }_{\mathrm{G}}$ is also present at new nodes during remyelination. Figure $5, k$ and $l$, shows two new nodes spanning a short internode at 14 days postinjection (dpi). Ankyrin ${ }_{\mathrm{G}}$ is highly colocalized with $\mathrm{Na}^{+}$channels at these sites.

We next investigated earlier events in the formation of these new nodes and the role of ankyrin $_{\mathrm{G}}$. Rat sciatic nerves were injected with lysolecithin and allowed to demyelinate and reach early stages of remyelination (11-13 d). They were then reinjected to disrupt early myelin, and nerves were dissected 1-7 d later. Immunostaining for $\mathrm{MAG}$ and $\mathrm{Na}^{+}$channels allowed identification of remyelinating regions and the channel clusters within them. The idea was to judge whether new clusters of $\mathrm{Na}^{+}$ channels that formed during the first round of remyelination remained focal (i.e., at uniformly high density over a sharply defined area) after the second injection (i.e., were well anchored) or were rapidly dispersed, indicating a lower level of stability than adult nodes. If the second injection occurred $p$ days after the first, and dissection was $q$ days after the second, the timing is characterized as $p: q$. Figure $5 m$ gives an example of a focal site, in this case a binary set of two clusters at 13:1 d. Figure $5 n$ shows an $\mathrm{Na}^{+}$ channel cluster that was diffuse at 11:2 d. In both cases, anti-MAG 
antibodies labeled only debris in the region of the cluster (data not shown), indicating that these were double-injected zones. Results at 11:q d are plotted in the bar graph in Figure 5 as the percentage of clusters that remain focal versus $q$. Results at 11:0 d are from a nerve that was singly injected and dissected at $11 \mathrm{dpi}$. Within just $2 \mathrm{~d}$ after the second injection, the percentage of focal sites dropped markedly. It then rose again, as a second wave of remyelination began. Remyelination is much faster because many Schwann cells that proliferated during the first wave remain in the region and are available to adhere to axons. The number of $\mathrm{Na}^{+}$channel clusters that could be found and reliably assigned to demyelinated axons was small. At 11:2 d, six such sites were found, and only one was focal. Most of the new clusters had most likely dispersed too much to be identified. The total number of clusters counted in the bar graph was 58. The decreased percentage at 11:2 d (relative to 11:0 or 11:1) was significant $(p<0.01)$. Thus, we conclude that the early clusters of $\mathrm{Na}^{+}$channels forming during remyelination are not as stable as the original adult clusters.

\section{Mobility of $\mathrm{Na}^{+}$channel clusters \\ during remyelination}

We attempted to build a model for $\mathrm{Na}^{+}$ channel clustering that is consistent with all of the data available and that can be tested quantitatively. An important element in this scheme involves the mobility of these channels at various stages of node formation. The axon-directed hypothesis predicts that $\mathrm{Na}^{+}$channels cluster immediately at nodal sites and then remain immobile. In contrast, the glial-directed hypothesis postulates that channels retain the ability to move along the axon as glial processes advance, despite any anchoring that may accompany the initial clustering. We thus require a measure of the rate and extent of any shifts in cluster location as nodes form. During development of the sciatic nerve, $\mathrm{Na}^{+}$channel clusters appear rapidly over the first postnatal week, but the animal, and thus the nerve, is also growing, making a test involving distance measurements difficult. Remyelination, on the other hand, can be done in the adult, in which axon growth is minimal. Rat sciatic nerves were demyelinated with lysolecithin, and nerves were dissected on several days during remyelination. Axons were stained with antibodies to pan $\mathrm{Na}^{+}$channels or to caspr1, in each case double-labeling with anti-MAG, which served as a marker for remyelinating Schwann cells. Distances across Schwann cells-internodes were measured between immunolabeled zones, and the results are shown in Figure 6 . If $\mathrm{Na}^{+}$channel clusters are found exclusively adjacent to caspr 1 regions, the two measurements should agree within 1-2 $\mu \mathrm{m}$, and this is found to be the case. The data in Figure 6 provide a measure of the rate at which Schwann cells grow longitudinally while they are ensheathing axons with myelin and influencing axonal $\mathrm{Na}^{+}$channels. The coincidence of the points based on $\mathrm{Na}^{+}$ channels and on caspr 1 shows that the channel cluster loci are closely linked to the Schwann cell length. The results thus also set conditions for rates of $\mathrm{Na}^{+}$channel cluster movement that must be met in any scheme for node formation. It has been demonstrated both in previous studies and here that, after $\sim 2$ months, internodal distances are constant and are $\sim 270 \mu \mathrm{m}$ (Dugandzija-Novakovic et al., 1995). The dashed line is drawn at that level, and this line thus represents the prediction of the "axon-directed" hypothesis. If the axon predetermines the nodal sites, one would expect them to form there and remain there, because the fiber itself is not growing. The experimental data clearly show that this is not the case, and the distance between clusters grows throughout this period and approaches $274 \mu \mathrm{m}$ as an asymptote.

\section{Discussion}

\section{The role of NrCAM}

This paper has focused on NrCAM, an Ig superfamily transmembrane protein, known to bind ankyrin $_{\mathrm{G}}$ within its intracellular 


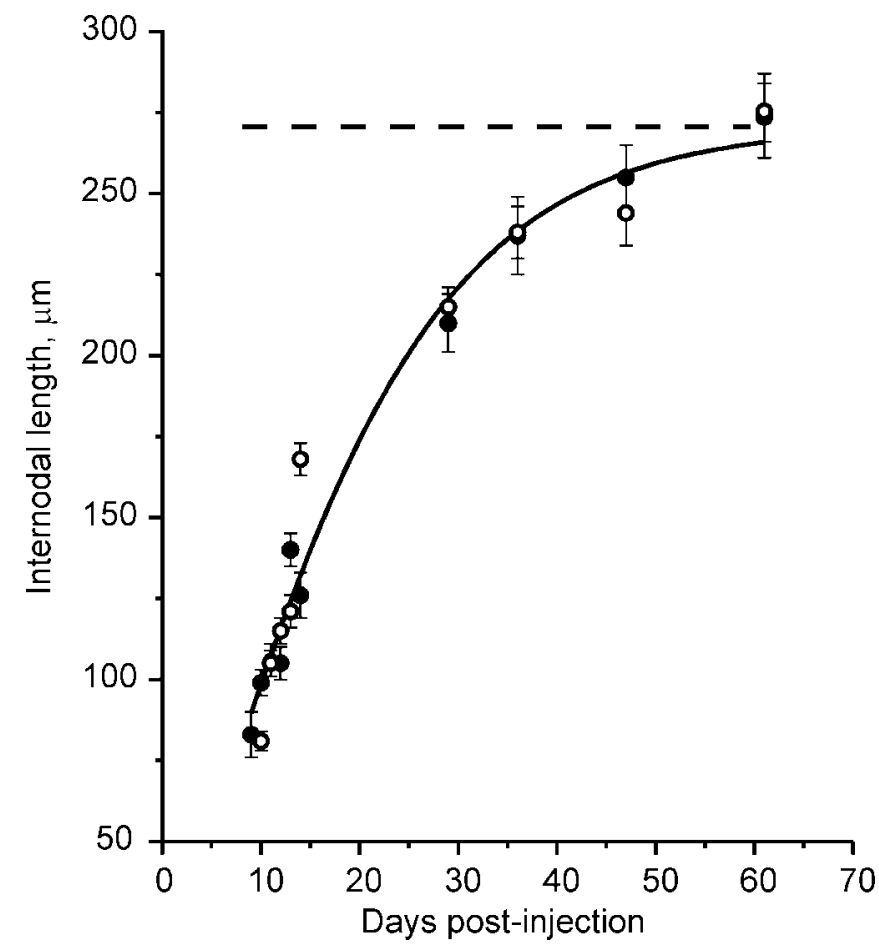

Figure 6. Internodal length plotted versus days after injection. Measurements were made between sites separated by a MAG-positive Schwann cell. The filled circles show distances measured between $\mathrm{Na}^{+}$channel clusters, and the open circles show distances measured between the edges of caspr1-positive sites. The solid curve is drawn to show trends. The dashed line is the prediction if the axon predetermined the final distance between new nodes after remyelination was complete. Total sites analyzed are as follows: MAG- caspr, 474; $\mathrm{MAG}-\mathrm{Na}^{+}$ channels, 577 .

domain. Lambert et al. (1997) showed that, at age P2, this protein was coclustered with ankyrin ${ }_{\mathrm{G}}$ at many sites in the sciatic nerve but was seen in the absence of ankyrin $_{\mathrm{G}}$ at others. Additionally, Lustig et al. (2001b) demonstrated that NrCAM fusion proteins inhibited $\mathrm{Na}^{+}$channel clustering in a myelinating coculture system. We now examined a series of developmental stages and quantitated the relative frequencies of different structures. The results indicate that NrCAM normally precedes $\mathrm{Na}^{+}$channel clustering at Schwann cell edges and lend support for the view that this protein is an early marker for nodes. Moreover, the functional relevance of $\mathrm{NrCAM}$ in node development is strengthened by the finding that genetic deletion of NrCAM results in a delay in both $\mathrm{Na}^{+}$channel and ankyrin $_{\mathrm{G}}$ clustering. This delay is not the result of any alteration in the rate of myelination, as judged by caspr1 localization. The results suggest that there is some redundancy or compensation in clustering mechanisms, because nodes ultimately form properly even in the absence of NrCAM. NrCAM does not act in a widespread manner within the neuron, e.g., to enhance synthesis of channels, but rather works through the local axon-glial interactions that define nodes. The timing of the delay in $\mathrm{Na}^{+}$channel clustering is similar to that with which the $\mathrm{Na}^{+}$channel isoform $\mathrm{Na}_{\mathrm{v}} 1.2$ is replaced by $\mathrm{Na}_{\mathrm{v}} 1.6$ in normal axons (Boiko et al., 2001). It is thus possible that NrCAM works predominantly on $\mathrm{Na}_{\mathrm{v}} 1.2$, but because the kinetics are so similar it would be difficult to test this idea.

In the NrCAM null mutants, conduction proceeded normally despite the delay in $\mathrm{Na}^{+}$channel localization at many nodes. This apparent paradox may be explained by a comparison of electrical properties of demyelinated and developing axons, both of which have a uniform distribution of $\mathrm{Na}^{+}$channels at a density suffi- cient in principle to support conduction. In focally demyelinated axons, however, conduction is blocked at the first heminode because the preceding node(s) cannot supply enough current to depolarize the high capacitance demyelinated zone (Shrager and Rubinstein, 1990). If developing axons behaved in similar manner, they would lose function when some Schwann cells initiated myelination, and others in the same fiber were immature. Clearly, this is not the case. Conduction in P2 axons is thus continuous, and the transition to saltatory conduction probably occurs only after all nodes have formed and myelin is more mature. Indeed, conduction velocity in developing rat sciatic nerve rises dramatically primarily after P6 (Vabnick and Shrager, 1998). Thus, missing $\mathrm{Na}^{+}$channel clusters at P2 have little effect and, because they are primarily gone by $\mathrm{P} 10$, there is no obvious physiological deficit in the NrCAM $(-/-)$ mice.

\section{Ankyrin $_{\mathrm{G}}$ in clustering and stabilization of $\mathrm{Na}^{+}$channels}

$\mathrm{Na}^{+}$channels at nodes are well anchored and, as shown here, can remain clustered for up to $9 \mathrm{~d}$ after myelin is disrupted, although by 2 weeks they are primarily dissipated (Dugandzija-Novakovic et al., 1995). This stability is likely attributable to their association with the underlying cytoskeleton through the adapter ankyrin G $_{\mathrm{G}}$. Does this link also play an essential role in the initial clustering of channels? In mice designed to block cerebellar expression of ankyrin $_{\mathrm{G}}$, Purkinje cells have disrupted initial segments, but an apparently different isoform is present at nodes, preventing conclusions about those sites (Jenkins and Bennett, 2001). The fact that nodal $\mathrm{Na}^{+}$channel clustering is delayed by deletion of the ankyrin $_{\mathrm{G}}$-binding protein $\mathrm{NrCAM}$ suggests a role in this mechanism. With the sensitivity of our immunofluorescence measurements, we could not resolve any difference in arrival times between $\mathrm{Na}^{+}$channels and ankyrin $_{\mathrm{G}}$. Thus, there is likely to be an initial reaction between these proteins with kinetics that are rapid compared with their transport along the axon to the glial edge. The double demyelination experiments show that this link may then be further stabilized over time, perhaps by reaction at multiple sites or through additional $\mathrm{Na}^{+}$channel subunits.

\section{Computational test of a model for $\mathrm{Na}^{+}$channel clustering}

Previous work suggested that $\mathrm{Na}^{+}$channels in an existing lowdensity axonal pool accumulated adjacent to the tips of myelinating glia, migrated as the glial processes elongated, and formed nodes of Ranvier by the fusion of neighboring clusters (Dugandzija-Novakovic et al., 1995; Tzoumaka et al., 1995; Vabnick et al., 1996; Lambert et al., 1997; Ching et al., 1999). We now consider the hypothesis that this process could occur if the rate of lateral diffusion of $\mathrm{Na}^{+}$channels is increased by glial association. Recently published results from the Bennett laboratory suggest a possible molecular mechanism. Several membrane proteins known to be complexed or colocalized with $\mathrm{Na}^{+}$channels are linked to the actin-spectrin cytoskeleton by $\operatorname{ankyrin}_{\mathrm{G}}$, and this association is controlled by phosphorylation of a critical intracellular tyrosine in the membrane protein (Garver et al., 1997; Jenkins et al., 2001; Malhotra et al., 2002). There is evidence that most $\mathrm{Na}^{+}$channels in excitable cell membranes are normally highly immobile (Stuhmer and Almers, 1982; Joe and Angelides, 1993) and thus probably anchored. The above findings then point to a clustering mechanism in which glial contact activates a tyrosine kinase that in turn frees these key axon membrane components from the cytoskeleton, effectively increasing their coefficient of lateral diffusion. $\mathrm{Na}^{+}$channels diffusing out of the contact zone might then again be bound by the combined ab- 
sence of the activated kinase and presence of a tyrosine phosphatase.

We tested the feasibility of such a mechanism with a computational model consisting of an axon in contact with a myelinating Schwann cell, in which virtually all critical parameters were under tight constraints from published measurements. The rate of formation and shape of axonal $\mathrm{Na}^{+}$channel clusters that developed at the edges of the Schwann cell were calculated and compared with results from immunofluorescence. Mathematically, $\mathrm{Na}^{+}$channel behavior was governed by the diffusion equation in one dimension [with coefficient $10^{-10} \mathrm{~cm}^{2} / \mathrm{sec}$ (Joe and Angelides, 1993)] plus a first-order tyrosine phosphorylation reaction whose rate constants (Mooney and Anderson, 1989; Mooney and Bordwell, 1992) favored the forward reaction under the Schwann cell and the reverse reaction outside the contact region. The Schwann cell grew longitudinally at a rate given by the data in Figure 6. The calculations, which will be presented in detail elsewhere, showed that the clustering process was predicted fairly well but required $\sim 24 \mathrm{hr}$ and resulted in a profile that was too diffuse. The finding that NrCAM arrives early and that its deletion results in a delay in both $\mathrm{Na}^{+}$channels and ankyrin ${ }_{\mathrm{G}}$ suggests that its role is to increase the rate of $\mathrm{Na}^{+}$channel immobilization at the Schwann cell edge by either concentrating an essential phosphatase or association with ankyrin $_{\mathrm{G}}$, which has multiple membrane-binding domains. Binding of NrCAM to ankyrin $_{\mathrm{G}}$ would be dependent on similar phosphorylationdephosphorylation reactions, and clustering mechanisms could thus be similar. Because this protein is smaller than the $\mathrm{Na}^{+}$ channel $\alpha$-subunit, it might diffuse more rapidly and thus cluster sooner. These ideas gained support when a fourfold increase in the rate of dephosphorylation reduced the time of cluster formation to $6 \mathrm{hr}$ (close to experimental estimates) and sharpened the density profile significantly. The model thus showed that this mechanism could, in principal, account for the clustering process and provided a possible role for NrCAM and perhaps other ankyrin $_{\mathrm{G}}$-binding proteins (neurofascin and $\beta$-subunits) as well.

As a cytoplasmic protein, ankyrin ${ }_{\mathrm{G}}$ is likely to have a high diffusion coefficient and thus not be rate limiting. It has not been possible to judge with certainty the relative roles of ankyrin ${ }_{\mathrm{G}}$ and its binding partners in early node formation. There are, for example, instances in which ankyrin ${ }_{\mathrm{G}}$ is found in the absence of neurofascin, as well as those in which neurofascin or NrCAM is found independently of ankyrin $_{\mathrm{G}}$ (Lambert et al., 1997; Jenkins and Bennett, 2002). However, it is difficult to reconcile the view that the coordinating molecule at presumptive nodes is the cytoplasmic protein ankyrin $_{\mathrm{G}}$, given the evidence that, at least in the PNS, glial contact is required to define the cluster sites. It seems more likely that an ankyrin $_{\mathrm{G}}$ ligand expressed on the axonal surface plays that role, and, from this work, NrCAM would seem a possible candidate.

Finally, these results provide additional evidence to distinguish between axon-directed and glial contact-directed mechanisms of node formation. The internodal length measurements in Figure 6 show clearly that, during remyelination, $\mathrm{Na}^{+}$channel clusters are not fixed in position but rather move increasingly farther apart as Schwann cells grow longitudinally. These sites are unequivocally defined as nodes by the adjacent caspr1 localization, and the entire structure moves together. It is hard to reconcile these findings with a system proposed for the CNS in which the axon sets the loci of nodes, with glia then filling in the gaps (Kaplan et al., 2001). We thus conclude that these sites are mobile, and their position is determined by adjacent glial processes.

\section{References}

Bennett V, Lambert S (1999) Physiological roles of axonal ankyrins in survival of premyelinated axons and localization of voltage-gated sodium channels. J Neurocytol 28:303-318.

Boiko T, Rasband MN, Levinson SR, Caldwell JH, Mandel G, Trimmer JS, Matthews G (2001) Compact myelin dictates the differential targeting of two sodium channel isoforms in the same axon. Neuron 30:91-104.

Ching W, Zanazzi G, Levinson SR, Salzer JL (1999) Clustering of neuronal sodium channels requires contact with myelinating Schwann cells. J Neurocytol 28:295-301.

Davis JQ, Bennett V (1994) Ankyrin binding activity shared by the neurofascin/L1/NrCAM family of nervous system cell adhesion molecules. J Biol Chem 269:27163-27166.

Dugandzija-Novakovic S, Koszowski AG, Levinson SR, Shrager P (1995) Clustering of Na channels and node of Ranvier formation in remyelinating axons. J Neurosci 15:492-502.

Einheber S, Zanazzi G, Ching W, Scherer S, Milner TA, Peles E, Salzer JL (1997) The axonal membrane protein Caspr, a homologue of neurexin IV, is a component of the septate-like paranodal junctions that assemble during myelination. J Cell Biol 139:1495-1506.

Garver TD, Ren Q, Tuvia S, Bennett V (1997) Tyrosine phosphorylation at a site highly conserved in the L1 family of cell adhesion molecules abolishes ankyrin binding and increases lateral mobility of neurofascin. J Cell Biol 137:703-714.

Grumet M, Mauro V, Burgoon MP, Edelman GM, Cunningham BA (1991) Structure of a new nervous system glycoprotein, Nr-CAM, and its relationship to subgroups of neural cell adhesion molecules. J Cell Biol 113:1399-1412.

Hall SM, Gregson NA (1971) The in vivo and ultrastructural effects of injection of lysophosphatidyl choline into myelinated peripheral nerve fibres of the adult mouse. J Cell Sci 9:769-789.

Jenkins SM, Bennett V (2001) Ankyrin-G coordinates assembly of the spectrin-based membrane skeleton, voltage-gated sodium channels, and L1 CAMs at Purkinje neuron initial segments. J Cell Biol 155:739-746.

Jenkins SM, Bennett V (2002) Developing nodes of Ranvier are defined by ankyrin-G clustering and are independent of paranodal axoglial adhesion. Proc Natl Acad Sci USA 99:2303-2308.

Jenkins SM, Kizhatil K, Kramarcy NR, Sen A, Sealock R, Bennett V (2001) FIGQY phosphorylation defines discrete populations of L1 cell adhesion molecules at sites of cell-cell contact and in migrating neurons. J Cell Sci 114:3823-3835.

Joe EH, Angelides KJ (1993) Clustering and mobility of voltage-dependent sodium channels during myelination. J Neurosci 13:2993-3005.

Kaplan MR, Cho MH, Ullian EM, Isom LL, Levinson SR, Barres BA (2001) Differential control of clustering of the sodium channels $\mathrm{Na}(\mathrm{v}) 1.2$ and $\mathrm{Na}(\mathrm{v}) 1.6$ at developing CNS nodes of Ranvier. Neuron 30:105-119.

Lambert S, Davis JQ, Bennett V (1997) Morphogenesis of the node of Ranvier: co-clusters of ankyrin and ankyrin-binding integral proteins define early developmental intermediates. J Neurosci 17:7025-7036.

Lustig M, Erskine L, Mason CA, Grumet M, Sakurai T (2001a) Nr-CAM expression in the developing mouse nervous system: ventral midline structures, specific fiber tracts, and neuropilar regions. J Comp Neurol 434:13-28.

Lustig M, Zanazzi G, Sakurai T, Blanco C, Levinson SR, Lambert S, Grumet M, Salzer JL (2001b) NrCAM and neurofascin interactions regulate ankyrin $\mathrm{G}$ and sodium channel clustering at the node of Ranvier. Curr Biol 11:1864-1869.

Malhotra JD, Kazen-Gillespie K, Hortsch M, Isom LL (2000) Sodium channel beta subunits mediate homophilic cell adhesion and recruit ankyrin to points of cell-cell contact. J Biol Chem 275:11383-11388.

Malhotra JD, Koopmann MC, Kazen-Gillespie KA, Fettman N, Hortsch M, Isom LL (2002) Structural requirements for interaction of sodium channel beta 1 subunits with ankyrin. J Biol Chem 277:26681-26688.

Mooney RA, Anderson DL (1989) Phosphorylation of the insulin receptor in permeabilized adipocytes is coupled to a rapid dephosphorylation reaction. J Biol Chem 264:6850-6857.

Mooney RA, Bordwell KL (1992) Differential dephosphorylation of the insulin receptor and its $160-\mathrm{kDa}$ substrate (pp160) in rat adipocytes. J Biol Chem 267:14054-14060.

Peles E, Nativ M, Lustig M, Grumet M, Schilling J, Martinez R, Plowman GD, Schlessinger J (1997) Identification of a novel contactin-associated 
transmembrane receptor with multiple domains implicated in proteinprotein interactions. EMBO J 16:978-988.

Peters LL, John KM, Lu FM, Eicher EM, Higgins A, Yialamas M, Turtzo LC, Otsuka AJ, Lux SE (1995) Ank3 (epithelial ankyrin), a widely distributed new member of the ankyrin gene family and the major ankyrin in kidney, is expressed in alternatively spliced forms, including forms that lack the repeat domain. J Cell Biol 130:313-330.

Poliak S, Gollan L, Martinez R, Custer A, Einheber S, Salzer JL, Trimmer JS, Shrager P, Peles E (1999) Caspr2, a new member of the neurexin family, is localized at the juxtaparanodes of myelinated axons and associates with $\mathrm{K}^{+}$channels. Neuron 24:1037-1047.

Poltorak M, Sadoul R, Keilhauer G, Landa C, Fahrig T, Schachner M (1987) Myelin-associated glycoprotein, a member of the L2/HNK-1 family of neural cell adhesion molecules, is involved in neuron-oligodendrocyte and oligodendrocyte-oligodendrocyte interaction. J Cell Biol 105:1893-1899.

Rasband MN, Peles E, Trimmer JS, Levinson SR, Lux SE, Shrager P (1999) Dependence of nodal sodium channel clustering on paranodal axoglial contact in the developing CNS. J Neurosci 19:7516-7528.

Rathjen FG, Wolff JM, Chang S, Bonhoeffer F, Raper JA (1987) Neurofascin: a novel chick cell-surface glycoprotein involved in neurite-neurite interactions. Cell 51:841-849.
Sakurai T, Lustig M, Babiarz J, Furley AJ, Tait S, Brophy PJ, Brown SA, Brown LY, Mason CA, Grumet M (2001) Overlapping functions of the cell adhesion molecules Nr-CAM and L1 in cerebellar granule cell development. J Cell Biol 154:1259-1273.

Shrager P, Rubinstein CT (1990) Optical measurement of conduction in single demyelinated axons. J Gen Physiol 95:867-889.

Stuhmer W, Almers W (1982) Photobleaching through glass micropipettes: sodium channels without lateral mobility in the sarcolemma of frog skeletal muscle. Proc Natl Acad Sci USA 79:946-950.

Tzoumaka E, Novakovic SD, Levinson SR, Shrager P (1995) $\mathrm{Na}^{+}$channel aggregation in remyelinating mouse sciatic axons following transection. Glia 15:188-194.

Vabnick I, Shrager P (1998) Ion channel redistribution and function during development of the myelinated axon. J Neurobiol 37:80-96.

Vabnick I, Novakovic SD, Levinson SR, Schachner M, Shrager P (1996) The clustering of axonal sodium channels during development of the peripheral nervous system. J Neurosci 16:4914-4922.

Vabnick I, Trimmer JS, Schwarz TL, Levinson SR, Risal D, Shrager P (1999) Dynamic potassium channel distributions during axonal development prevent aberrant firing patterns. J Neurosci 19:747-758. 